\title{
Exploring Race Hate Crime Reporting in Wales Following Brexit
}

\author{
Gareth Cuerden ${ }^{1} \&$ Colin Rogers ${ }^{1}$ \\ ${ }^{1}$ University of South Wales, Pontypridd, UK \\ Correspondence: Colin Rogers, University of South Wales, Pontypridd, UK. E-mail: \\ colin.rogers@southwales.ac.uk \\ Received: November 1, 2016 \\ Accepted: November 9, 2016 \\ Online Published: January 21, 2017 \\ doi:10.5539/res.v9n1p158 \\ URL: http://dx.doi.org/10.5539/res.v9n1p158
}

\begin{abstract}
Most countries consist of many diverse races and cultures, based on historical political decisions, wars or economic changes. Throughout Europe over the past decades the policy of free movement for work as part of the EU agreements has encouraged this activity. Indeed this has been a fundamental idea behind the European Union ever since its inception. However, what can the consequences be for those individuals who, encouraged by such policies, find themselves located in a country which has decided to no longer be part of that system? In particular what impact does this decision appear to have on the way those considered to be "racially different" are treated by others? This article explores the impact the recent decision by Great Britain took to leave the EU (so called Brexit) and its impact upon the number of racially recorded hate crimes in Wales. Using examples from terrorist incidents in Europe, along with the Brexit result, as examples, it provides clear evidence that when certain incidents occur in wider society, there is an impact upon the way in which so called non-indigenous people are treated, which results in an increase in criminality. These results will have resonance for other countries with a mixed population, as well as having implications for those agencies involved in the protection and safety of all inhabitants in their country.
\end{abstract}

Keywords: hate crime, police, racial Abuse

\section{Introduction}

The recent decision by the electorate in the United Kingdom referendum to leave the European Union has impacted upon social and political thought in the country. Economically, ties with Europe will of course hopefully remain, as well as other aspects of the former union, particularly when it comes to policing for local, national and international arrangements.

During the so called Brexit debates, however, there were claims and counterclaims regarding the topic of immigration. This political issue seems to have been a major contributing factor in the decision to leave the EU, but it may also have encouraged some individuals to engage in open hostility towards immigrants across the country. For example, incidents have been reported in the media of racial abuse being hurled at minority ethnic individuals in places such as Manchester, Basingstoke, and Cardiff amongst many other places, as well as online race hate abuse towards individuals. This article will consider the position regarding the number of recorded race hate crime referrals since 2014, and will utilise the position in Wales for discussion. Firstly, however, there is a need to examine just what is meant the term Race Hate Crime.

Notwithstanding any other definition or clauses in different Acts of Parliament, the most commonly used definition of a Race Hate Crime in England and Wales is as follows:

Any criminal offence, perceived by the victim or any other person, to be motivated by hostility or prejudice based on a person's race or perceived race.

(Home Office, 2003)

Such is the seriousness of this offence that the powers of this Act enable an increase in the sentence imposed of up to fifty percent. Despite what appears to be a clear cut definition of recording purposes, defining hate crime is a complex task. In particular, the first problem relates to the word "hate" and what exactly is meant by this term. When we talk about hate are we including such emotions as prejudice, bias, bigotry, anger or just a mere aversion to others? On the other hand, we may mean all of these things. In addition, it is the perceptions of the person subject to abuse, or any other person witnessing that abuse, that is a major important constituent of this type of 
activity. This too, can be slightly problematic. Therefore, we need to carefully understand just what is meant by the term race hate crime, because as with all other aspects of crime figures, they can be contested. We need to acknowledge this because everything that we associate with race hate crime depends upon how we define and conceptualise it.

\section{Method}

Despite this, the indicator most utilised for understanding rates of race hate crime in England and Wales are the incidents reported to the police, who then refer them on to various other agencies for information and action. The situation within Wales is that victims of hate crime can report the occurrences directly to the Police primarily using the 101 or 999 telephone numbers or other methods. Victims also have the option of submitting a report online directly to the Police through "True Vision" the England and Wales third party reporting website. Victims may also report directly to Victim Support (Cymru) who have been commissioned by the Welsh Government to support victims of hate within Wales and are the National Hate Crime Report and Support Centre Wales. The recording system in use in Wales means that when an incident is reported to the police, Victim Crime Data is transferred electronically and automatically from the four Welsh Police Forces using a data sharing agreement which is confidential, and involves anonymised data being analysed using an extract report produced by the Victim Support Cymru National Hate Crime Report and Support Centre. Of course, when considering official statistics, we must remember that they are in fact partial, because many people do not report such incidents for a variety of reasons including not trusting the police, fear of reprisals etc. In addition, when trying to make inferences from quantitative data alone, it is sometimes difficult to ascribe particular rises or spikes in data to a particular incident or incidents. The methodology employed for this research therefore involves an analysis of reported and recorded race hate crime figures as reported to agencies across Wales over the discussed defined period of time.

\section{Results}

On the 13th November 2016 Paris and Saint-Denis in France were targeted in a coordinated attack by the Islamic State of Iraq and the Levant (ISIL), who claimed responsibility for the attacks in response to French Airstrikes on ISIL targets in Syria and Iraq. 130 people were killed and 368 people were injured during the attacks, which took the form of 3 suicide bombers in addition to mass shootings at cafes, restaurants and the Bataclan Theatre. The attacks sparked a 3-month state of emergency across France which included a restriction on public demonstrations, and a series of counter programmes which included the Police being able to search without Warrants, place residents under house-arrest and to block websites that could be linked to the encouraging of acts of terrorism. The French response also included a secondary airstrike against ISIL which allegedly resulted in the death of the "suspected" lead operative for the Paris and Saint-Denis attacks.

Coverage of the attacks was widespread across all major media companies and publications within the UK and Europe, yet it was felt that the coverage portrayed an uneven reporting of important stories such as the Lebanon attacks on the 12th November 2015 receiving far less or no coverage within the UK and Europe, which has heighted media cynicism in the Middle East Aljazeera (03/04/2016). Notably there was a prominent social media campaign within the UK in show support to victims in France in addition to the illumination of the National Gallery in Trafalgar Square London, all of which have contributed to a wide awareness of the attacks within the UK and Wales.

Whether or not the incidents encouraged greater levels of crime was a question for this research. By analysing data obtained from the National Hate Crime Report and Support Centre Wales run by Victim Support Cymru it was possible to identify any change in reporting. Graph A below illustrates the figures for all Wales Hate Crime referrals for the month of November 2015, which includes the figures for the time of the attack in Paris. 


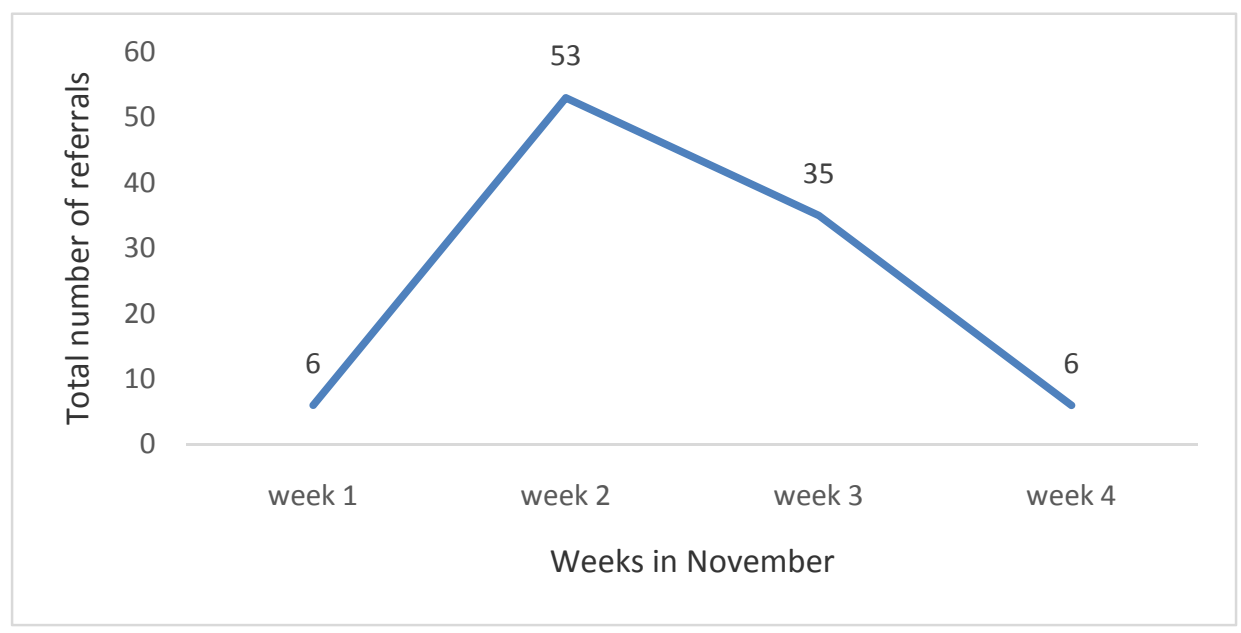

Figure 1. Wales race hate crime referrals (November, 2015)

Source: Hate Crime Wales.

This data appears to show an increase in the number of referrals for race hate crime at the time of the Paris attacks, before returning to more stabilized numbers in the following week or so. However, it was also important to consider any effects similar incidents may have had upon the reporting of racially motivated hate crimes.

On the 22nd March 2016 coordinated attacks took place Brussels Airport Zaventem and Maalbeek Metro Station. ISIL claimed responsibility for the attacks which killed 32 people and injured over 300 people. It was suggested after the attacks that some of the perpetrators involved in the Paris Attacks were based in Molenbeek Brussels. Similar to that of the Paris Attacks, UK and European media covered the story extensively with again, a specific social media campaign to mourn the victims and highlight the events.

When referral data for March 2016 was considered as shown below in Figure 2, we can see that the recorded incidents peak during week 4 , the time period when the attacks took place, which clearly highlights a possible correlation between the events and the referral increase.

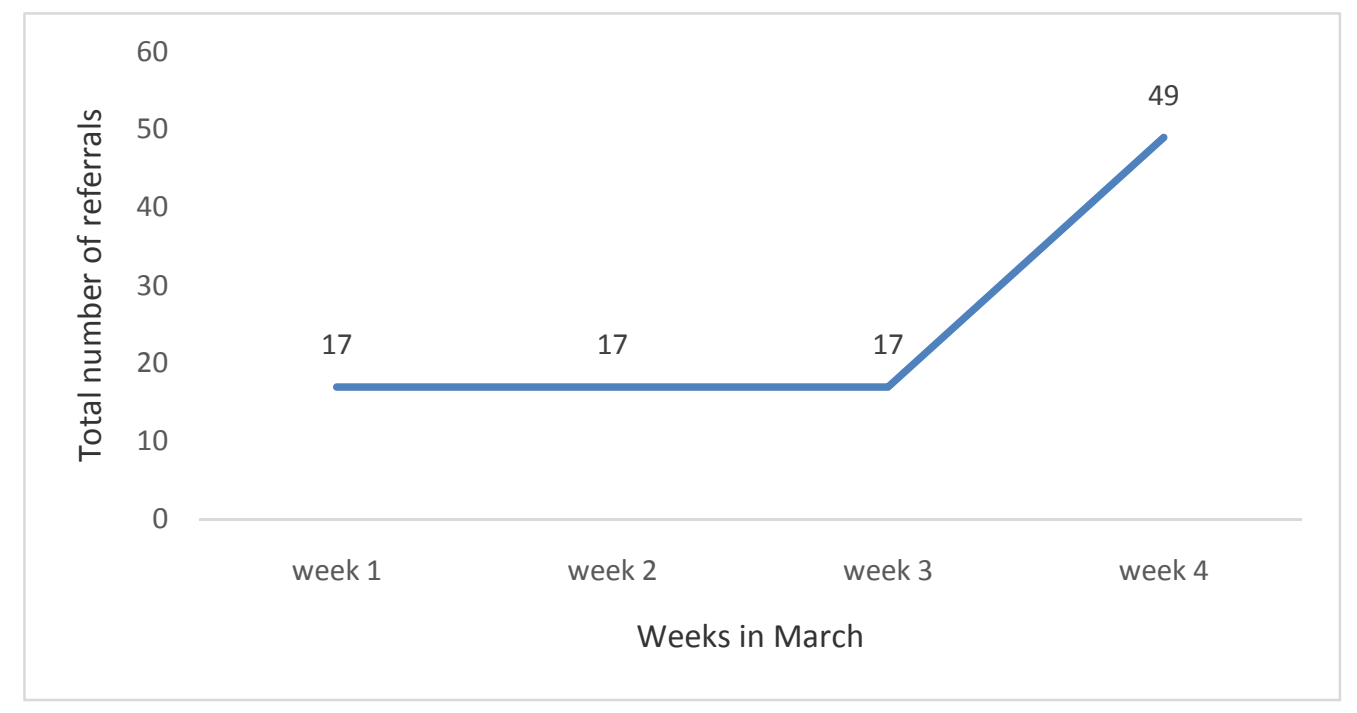

Figure 2. Wales race hate crime referrals (March, 2016)

Source: Hate Crime Wales. 
What the data appears to be indicating is that at times of particular incidents, such as terrorist attacks or other politically motivated incidents, race hate referrals tend to rise. The question of causality remains a problem in that it is not possible to directly link the rise in the referrals to a particular incident, though it is likely that these incidents influence people's attitudes and actions and the data may be reflecting this.

\section{The Brexit Vote and Hate Crime Figures in Wales.}

If we now consider the recent Brexit vote and recorded race hate crime figures in Wales, we can produce the following time sequence chart that illustrates recorded race hate crime referrals for all four Welsh police forces since April 2014. This is seen in the Figure 3 below.

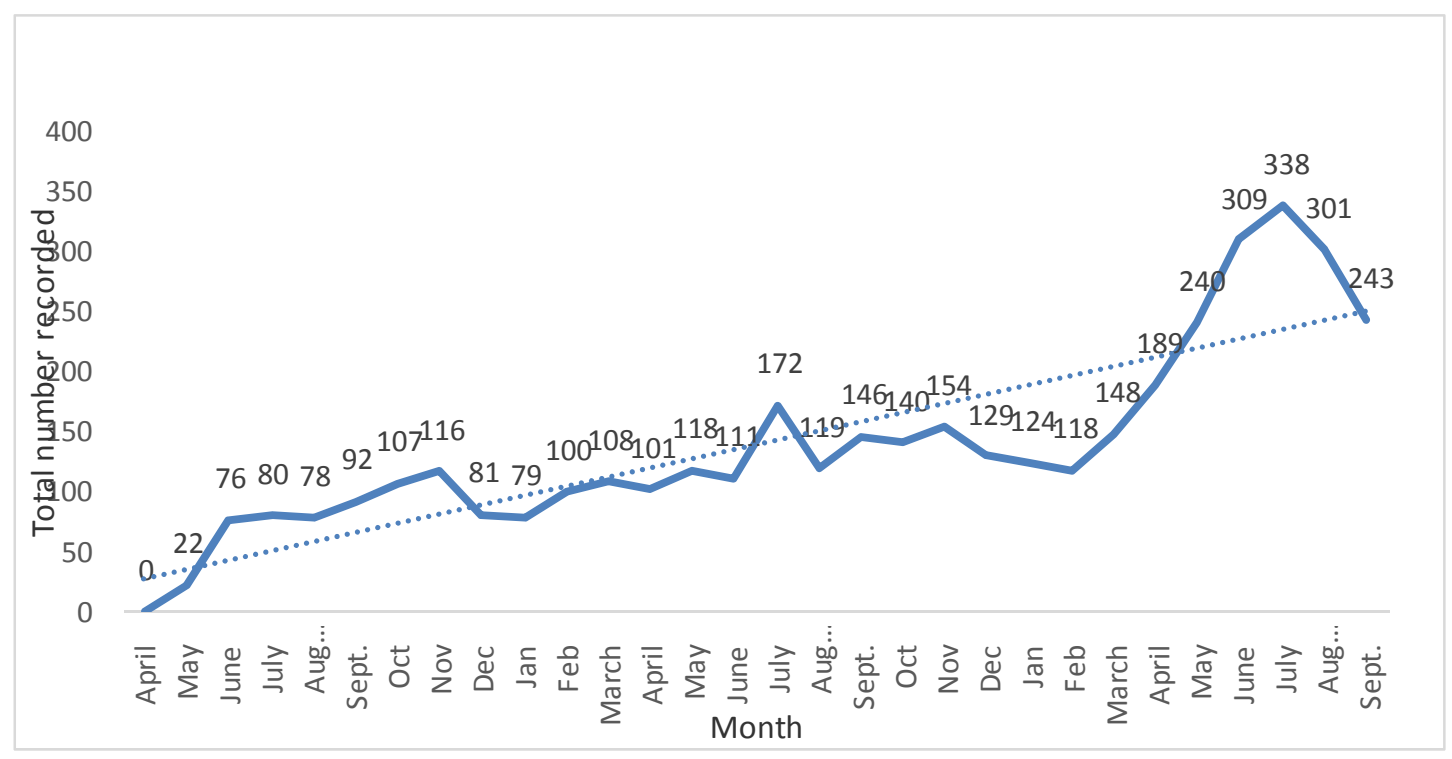

Figure 3. Recorded racially motivated hate crime referral (all wales) from April 2014

The general trend seen in this data is one of increasing reporting of such offences. However, this may of course be the case that more people are willing to report such incidents as there is now a mechanism for recording them, rather than a dramatic increase in the number of offences since 2014 due to more race hate crime within communities. Notwithstanding that, there is clear evidence that the recording of such offences dramatically increases at certain times, and that this coincides with certain national and international events, including terrorist attacks etc. If one accepts this to be the case, and given the large amount of media attention given to the EU referendum, one can see that since April 2016, a steady increase in the number of these recorded offences took place, from 189 to 240 recorded instances. This in turn rose steadily to 309 incidents during June the month of the referendum and the decision to leave the EU, increasing to 338 the month after. However, since that month the numbers are declining, although remaining high. This may in part be applicable to the high media reporting of such events and possible political stabilisation once the idea of Brexit took hold.

\section{Discussion}

Victimology began to emerge as a distinct area of study, with identified categories of individuals being more prone to being victims of crime based on their Social, Biological or Psychological typology (Von Hentig, 1941) and that victimisation was the process of social interaction based on the relationships and interactions between the perpetrator and the victim (Von Hentig, 1948).

Mendelsohn (1947) looked at pre-existing interpersonal relationships between the victim and offender and started to draw conclusions based on the degree of guilt and self-blame a victim attributed to becoming a victim, which contributed to the concept of victim precipitation, where the victim initiates their own victimisation. This was reinforced most notably by Wolfgang (1958), who argued that the majority of homicides in Philadelphia US, were victim precipitated either through a provocation of the offender or an unconscious desire to commit suicide and were generally known to each other. Ellenberger (1954) considered how social, physical and occupational factors 
could increase the likelihood of being a victim. Schafer (1968) extended this work yet there was a clear distinction between victim typologies that held a greater level of responsibility over becoming a victim and those that were simply easy targets and held no responsibility such as the biologically weak and socially weak, which would include people with a disability and racial immigrants and minorities, which we would associate as "hate crime victims".

Miers (1989) focussed on Positivist Victimology, identifying factors that contribute to non-random victimisation and identified victims who are prone to contributing to their own victimisation through the victim precipitation theory. The theory suggests that the victim exhibits behaviours or hold characteristics that encourage the attack. This theory may be linked to the notion of Hate Crime (as a legal definition) as including victims of crime based on their race, religion, disability, sexual orientation or gender identity driven by a prejudice. The question, of course, is whether these factors could be considered viable categories of typology within the arena of victimology. Dorkin, et al. (1996) considered racial differences between victimisation and found that black people were victimised greater than white people. This was reinforced by Rand et al. (1997) who found non-fatal victimisation among black women was higher than white women. Herek, Gills and Cogan (1999) suggested that these victim experiences of victimology were linked to community-level factors where anti-black crimes were committed within organised white communities and anti-white crimes stemming from more frequently disorganised minority communities. It is therefore suggestive that race is a typology of victimology and offending choice, but also that exposure to more dangerous environments could lead to a higher likelihood of becoming a target (Stark, 1987). Disabilities have also been considered within the realms of victimology as that of race, with Allen (2012) considering the impact of victimisation upon the disabled, suggesting that a physical or mental disability is enough to increase the desirability for an offender when considering the absence of a capable guardian and availability of a suitable target as with the Routine Activities Theory (Cohen \& Felson, 1987). Health Canada (2004) in a wider context linked vulnerability to victimisation when a statement was published outlining how individuals with a physical, sensory or cognitive impairment may be perceived by offenders as having a higher target rate based on the vulnerability due to a lesser ability to deter offenders, therefore supporting the Routine Activities Theory. Reid (2004) evidenced this through research that showed victims with a limitation such as a visual impairment would be twice as likely to be a victim of sexual assault, robbery, violence and physical assault than someone without any limitation. Reinforced further by Scherer (2011) finding college students with a disability were one and a half times more likely to be a victim of sexual assault than non-disabled victims. It is quite clear that victims with a disability are viewed as more attractive victims based on a perception of vulnerability or ease of offending and meets the typology for victimology. Herek (2009) drew conclusions that crimes against gay males were more likely than any other sexual minority to experience anti-gay violence; which provided a platform to link typology to sexual orientation. This consideration was reinforced by findings of the National Coalition of Anti Violence Programmes (NCANP, 2010) linking sexual orientation and gender identity to higher rates of open targeting by offenders. This open identity which could loosely be extended to lifestyle choice could support the Lifestyle Choice Theory as a result of being targeted due to that identity (Dempsey et al., 2006) and further considered when measuring targeted violence against identifiable groups such as "Goth" (Garland \& Chakraborti, 2009).

However, the problem of causality is one that many statisticians and social scientists have struggled with for many years. By causality we mean just how one proves that one stimulus can cause an effect elsewhere. This is particularly so when discussing social interactions with all the complexities involved in that topic. The question therefore is this has the recent vote to leave the EU directly led to an increase in the number of recorded race hate crimes? Jacobs and Potter (1998) have attempted to introduce a model that tries to explain causality and it is worthy of a brief explanation here. The model can be seen in the following table.

The horizontal axis shows the degree of the offenders prejudice (high or low) and the vertical axis shows the strength of the causal relationship.

Table 1. Model of understanding hate crime

\begin{tabular}{lccc}
\hline & High & High Prejudice/High Causation & Low Prejudice/High Causation \\
\cline { 2 - 4 } Strength of Causal relationship & High Prejudice/Low Causation & Low Prejudice/Low Causation. \\
& Low & High & Low \\
\hline
\end{tabular}

Source: Jacobs and Potter (1998). 
This model attempts to compartmentalise different types of hate crime, so that an example of high crime/high causation may be that of an extremist deliberately attacking people with a bomb at a venue used by a particular group. The low prejudice/low causation box represent many incidents or offences that may arise from ad hoc disputes or short tempers, but are neither the product of strongly causal relationships related to the incidents in question. Examples of this type of incident could be a long running dispute over a boundary fence between a black family and a white family, whereby racial insults are hurled by both as the incident escalates. Notwithstanding these different types of race hate categories, what this model illustrates is that defining race hate crime is complex and that the causality of one incident to the increase of referrals is not as straightforward as it seems. Despite the problems highlighted, there are however, incidents that may appear to be linked to the increase in referrals of race hate crime, and such incidents are discussed below.

Clearly the figures examined within this research appear to demonstrate that there has been a rise across all of Wales in the number of recorded race hate crime referrals in the past months, at a time when topics surrounding the EU referendum such as immigration, unemployment and the economic future of the UK as whole have been under discussion. Examination of this data longitudinally suggests that such events as terrorist attacks or other incidents involving perceptions of threats coincide with an increased numbers of referrals.

There is of course a media influence upon reporting. With the news of a "leave" decision in the EU, The Independent Newspaper published on 27th June 2016 a newspaperwhich covered stories outlining an increase in "no more Polish vermin" signs being posted through letter boxes, in addition to non-UK residents being approached and told to either go home or get a Visa. These trends were also carried in publications such as the International Business Times (25th June 2016) which focussed on Welsh Business woman Shazia Awan, who was told shortly after the result to "pack her bags and go home". In addition, the Telegraph (26th June 2016) published Baroness Warsi suggesting that the "Divisive and Xenophobic" Leave Campaign bore the responsibility for the current rise in disturbing hate crimes since the vote to leave the EU. Quisenberry (2001) coined the term "extra-legal influences" in which it was suggested based on research carried out using Vanderbilt Television News Archives and FBI Uniform Crime Reports that when press stories focus on a particular protected characteristic group such as racism there would be an increased level of reporting amongst that category.

For the police this means an increase in the amount of resources they have to expend in dealing with victims of such offences and bringing those responsible to justice. More importantly, the victims of such offences need to be supported and reassured that this is not part of a greater and more general trend of race hate across the country. Agencies that therefore provide support to victims of this, and other crimes, will of course, feel the pressure to provide this support, especially in times when organisations are still dealing with the effects of austerity measures. There may of course be resonance in these findings for other countries experiencing similar political upheavals.

Race hate crime is particularly divisive within communities, and owes its existence, in part at least, to ignorance and misunderstanding. Cohesive communities are the bedrock of civilised society (Halpern, 2007), a society where in the democratic policing model thrives, as it works by policing with and through communities. Increased numbers of race hate crime referrals should not be dismissed or underestimated as to their ability to negatively influence perceptions of community and this in turn may impact upon how the police are perceived within their communities. This research indicates that public agencies, such as the police and others, should be aware of the collateral impact upon communities of wider incidents that occur in the political, social, technological and economic sphere.

\section{References}

Aljazeera, T. F. (2016). Media Coverage of the Paris and Brussels Attacks-What was different. Retrieved November 1, 2016, from http://studies.aljazeera.net/en/reports/2016/04/media-coverage-paris-brussels-attacks-160403101940528.ht $\mathrm{ml}$

Allport, G. A. (1979). The Nature of Prejudice. In Perseus Books. New Jersey, USA.

Camilla, T. (2016). Spate of Racist Attacks Blamed on Brexit Vote. Telegraph Newspaper.

Cohen, L. E., \& Felson, M. (1979). Social Change and Crime Risk Trends: A Routine Activity Approach. American Sociological Review, 44(4), 588-608. https://doi.org/10.2307/2094589

Dempsey, J., Fireman, G., \& Wang, E. (2006). Transitioning Out of Peer Victimization in School Children: Gender and Behavioral Characteristics. Journal of Psychopathology and Behavioral Assessment, 28, 271-280. https://doi.org/10.1007/s10862-005-9014-5 
Dorkin, A., Wiersema, B., Loftin, C., \& McDowal, D. (1996). Statistical Handbook on Violence in America. Phoenix AZ: Oryz Press.

Felson, M. (1987). Routine Activities and Crime Prevention in the Developing Metropolis. Criminology, 25, 911-931. https://doi.org/10.1111/j.1745-9125.1987.tb00825.x

Garland, J., \& Chakraborti, N. (2009). Hate Crime: Impact, Causes, and Consequences. London: Sage.

Halpern, D. (2007). Social Capital. Cambridge: Polity Press.

Harriet, A. (2016). Brexit: Wave of hate crime and racial abuse after the EU Referendum. In Independent Newspaper.

Herek, G. M. (2009). Hate crimes and stigma-related experiences among sexual minority adults in the United States: Prevalence estimates from a national probability sample. Journal of Interpersonal Violence, 24, 54-74. https://doi.org/10.1177/0886260508316477

Herek, G. M., Gillis, J. R., \& Cogan, J. C. (2009). Internalized stigma among sexual minority adults: Insights from a social psychological perspective. Journal of Counselling Psychology, 56, 32-43. https://doi.org/10.1037/a0014672

Home Office. (2003). Criminal Justice Act. London: Home Office.

Jacobs, J. B., \& Potter, K. (1998). Hate Crimes: Criminal Law and Identity Problems. New York: OU Press.

Mendelsohn, B. (1947). Pioneers in Victimology. Victimology: An International Journal, 1(2), 189-228.

Miers, D. (1989). Positivist Victimology: A critique. International Review of Victimology, 1, 3-32. https://doi.org/10.1177/026975808900100102

Quisenberry, P. (2001). Television News Coverage and its effects on the recording of Hate Crime (Proquest Dissertation).

Rand, M. R., Lynch, J. P., \& Canter, D. (1997). Criminal Victimisation 1973-1995, Bureau of Justice Statistics. In National Crime Victimisation Survey. Washington, D.C. US Department of Justice.

Reid, G. (2004). Abuse of People with Disabilities. Brochured'information pour fourniseurs de services.

Samantha, P. (2016). Brexit Racist Blowback: Muslim women targeted for abuse after EU Referendum Vote. International Business Times.

Stark. (1987). Deviant Places: A Theory or the Ecology of Crime. Criminology, 25(4), 893-910. https://doi.org/10.1111/j.1745-9125.1987.tb00824.x

The National Clearinghouse on Family Violence. (2004). Violence against Women with Disabilities. Ottawa, ON: Government of Canada.

Von, H. (1941). Remarks on the Interaction of the Perpetrator and Victim. Journal of Criminal Law and Criminology, 31(3).

Von, Hentig. (1948). The Criminal and His Victim. Journal of Criminal Law and Criminology, 31(3). North Western University School of Law Scholarly Commons.

Wolfgang, M. F. (1958). Victim Precipitated Criminal Homicide. Criminology \& Police Science, 1.

\section{Copyrights}

Copyright for this article is retained by the author(s), with first publication rights granted to the journal.

This is an open-access article distributed under the terms and conditions of the Creative Commons Attribution license (http://creativecommons.org/licenses/by/4.0/). 